\title{
Erratum to: Extremity Injury
}

\section{Scott Ryan, Lisa Ceglia and Charles Cassidy}

Erratum to: Chapter 30 in: Fred A. Luchette \& Jay A. Yelon (eds), Geriatric Trauma and Critical Care https://link.springer.com/chapter/10.1007/978-3-319-48687-1_30

The original version of Chapter 30 was inadvertently published with one author name "Charles Cassidy" instead of three author names "Scott Ryan*, Lisa Ceglia, Charles Cassidy". The chapter has been updated.

The updated online version of this chapter can be found at https://link.springer.com/chapter/10.1007/978-3-319-48687-1_30

S. Ryan $(\bowtie) \cdot$ L. Ceglia $\bullet$ C. Cassidy Department of Orthopaedic Surgery, Tufts Medical Center, 800 Washington Street, \#306, Boston, MA 02111, USA

e-mail: SRyan3@tuftsmedicalcenter.org 